\title{
EFECTO DEL FUMARATO HIDROGENADO DE TIAMULINA SOBRE LA PERSISTENCIA DEL MYCOPLASMA SYNOVIAE EN AVES DE POSTURA COMERCIAL
}

\author{
Adolfo Saldaña ${ }^{1}$, Eliana Icochea ${ }^{2}$, Norma Noé, Antonio Ramírez y Sharon Levisohn ${ }^{3}$
}

Effect of tiamulin hydrogen fumarate treatmennt on persistence of Mycoplasma synoviae in commercial Mycoplasma hyopneumoniae laying hens.

Mycoplasma synoviae is an economically significant pathogen of commercial poultry worldwide, which generally produces subclinical to mild upper respiratory tract or synovitis infections with lateral and vertical transmission. The effect of tiamulin hydrogen fumarate treatment on agent persistence in the trachea of $M$. synoviae infected layers was evaluated. Two groups of eight, 30 week old $M$. synoviae infected (PCR positive) commercial layers (Isabrown line), were studied. The first group received two three day treatments of tiamulin $(33 \mathrm{mg} / \mathrm{kg}$ administered in the drinking water) with a 27 day interval, while the second group was not medicated. Tracheal swabs were taken weekly for two months. All 16 samples were tested by PCR, using pools of four tracheal swabs, and found positive to $M$. synoviae confirming pathogen persistence in the trachea of both treated and untreated birds. lens.

Key words: Mycoplasma synoviae, PCR, Tiamulin Hydrogen Fumarate, laying

El Mycoplasma synoviae es un patógeno de importancia económica en la industria avícola del mundo, generalmente causante de infecciones subclínicas a leves del tracto respiratorio superior o sinovitis infecciosa, con capacidad de transmisión horizontal y vertical. Se ejecutó un programa de medicación con Fumarato Hidrogenado de Tiamulina en gallinas de postura infectadas naturalmente con Mycoplasma synoviae con la finalidad de evaluar su influencia sobre la persistencia del agente a nivel de mucosa traqueal. Con esta finalidad dieciséis aves de postura comercial (línea Isabrown), de 30 semanas de edad, infectadas con Mycoplasma synoviae (PCR positivas) fueron separadas en dos grupos experimentales, uno con tratamiento y otro sin tratamiento. La tiamulina fue administrada en el agua de bebida a razón de $33 \mathrm{mg} / \mathrm{kg}$ por tres días consecutivos, dos veces con un intervalo de 27 días. Se realizaron hisopados traqueales, semanalmente y durante un periodo de dos meses. Todas las muestras fueron trabajadas en pools de cuatro muestras/pool, analizados por la prueba PCR. Después de la medicación todos los pools $16 / 16$ fueron positivos a Mycoplasma synoviae. Estos resultados confirman la persistencia del Mycoplasma synoviae en la mucosa traqueal de aves medicadas.

Palabras clave: Mycoplasma synoviae, PCR, Fumarato Hidrogenado de Tiamulina, gallinas de postura.

\footnotetext{
${ }^{1}$ Práctica privada.

${ }^{2}$ UNMSM-FMV Profesora Principal.E-mail:d170022@unmsm.edu.pe; d170027@unmsm.edu.pe. ${ }^{3}$ Instituto Veterinario Kimron, Bet-Dagan, Israel.

Trabajo auspiciado por el Proyecto TA-MOV-95-EII-220. USAID. Sub-contrato FMV - Instituto Vet. Kimron de Bet-Dagan, Israel.
} 


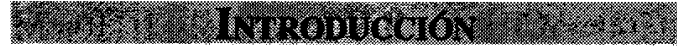

La crianza de aves como actividad económica enfrenta una serie de problemas que limitan su desarrollo, tal es el caso de las enfermedades infecciosas. Una en particular, la infección por Mycoplasma synoviae (M. synoviae) puede producir severas pérdidas económicas; al aumentar el porcentaje de descartes por cojeras y pobre ganancia de peso, afectando principalmente a granjas de pollos y pavos.

La estructura piramidal de la industria avícola así como la posibilidad de transmisión vertical hacen que el $M$. synoviae sea una amenaza para los planteles de reproductoras y abuelas en el ámbito mundial. Las normas sanitarias de los países exigen planteles libres de mycoplasma, por esta razón se han desarrollado diferentes técnicas de diagnóstico, en especial los métodos moleculares debido a que los procedimientos de diagnóstico tradicionales basados en el cultivo muestran dificultades para el aislamiento del agente y los de serología problemas de sensibilidad y especificidad.

El uso de drogas antimicrobianas es el principal medio de tratamiento contra $M$. synoviae, con el fin de prevenir la presentación de las formas graves de esta enfermedad. Para la adecuada elección de la droga antibacterial se debe considerar el sitio de acción de la droga dentro de la estructura del $M$. synoviae, que la droga alcance las concentraciones inhibitorias mínimas en los tejidos donde el agente produce mayor daño y poca capacidad para desarrollar resistencia por el $M$. synoviae. Considerando los factores mencionados se ha recomendado el uso de antibióticos como la clortetraciclina, los macrólidos y la tiamulina capaces de inhibir la síntesis proteica del $M$. synoviae y que logran concentraciones importantes a nivel de tejidos respiratorio, reproductivo $y$ articular, así como las quinolonas de tercera generación que actúan sobre la replicación y trascripción del ADN del M.synoviae.
En el Perú la existencia de áreas dedicadas a la industria avícola densamente pobladas con grandes parvadas, muy próximas entre ellas con un intenso tráfico humano y con crianzas de traspatio, favorece la diseminación horizontal del agente. Se ha demostrado que casi el $100 \%$ de las gallinas de postura comercial de la provincia de Chincha se encuentran infectadas con $M$. synoviae (Díaz, 1999; Gonzáles, 1999).

Vista la importancia económica y epidemiológica del $M$. synoviae y la existencia de una prueba de alta sensibilidad y especificidad como es la prueba de Reacción en Cadena por la Polimerasa (PCR) para un diagnóstico de infecciones por mycoplasma, el presente trabajo tuvo como objetivo evaluar la influencia de la medicación con Fumarato Hidrogenado de Tiamulina sobre la persistencia de $M$. synoviae en la tráquea de gallinas de postura comercial con infección natural utilizando al PCR como prueba diagnóstica.

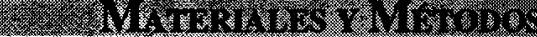

La crianza, el muestreo de las aves y las pruebas de PCR se realizaron en el Laboratorio de Patología Aviar de la Facultad de Medicina Veterinaria (FMV) Universidad Nacional Mayor de San Marcos.

Se emplearon 16 aves de postura comercial (línea Isabrown) de 30 semanas de edad, identificadas individualmente mediante bandas alares e infectadas naturalmente con $M$. synoviae, detectado por la prueba PCR a las 11 semanas de edad.

Se utilizó el antibiótico Fumarato Hidrogenado de Tiamulina administrado en el agua de bebida al $0.025 \%$.

Las aves fueron divididas en dos grupos de 8 aves cada uno:

Grupo A: Recibieron el tratamiento con Fumarato Hidrogenado de Tiamulina. 
Grupo B: No recibieron el tratamiento con Fumarato Hidrogenado de Tiamulina.

La crianza de las aves se realizó en jaulas individuales y recibieron durante toda la fase experimental el alimento comercial especialmente formulado según la edad de las aves.

El Fumarato Hidrogenado de Tiamulina fue administrado vía agua de bebida a razón de $33 \mathrm{mg} / \mathrm{kg}$ por tres días consecutivos durante el primer mes. El tratamiento fue repetido nuevamente durante tres días consecutivos del segundo mes.

Se tomaron muestras traqueales con torundas estériles, las que fueron colocadas en tubos igualmente estériles y transportadas al laboratorio en cajas térmicas con hielo seco. Dicho muestreo fue realizado el día previo a la primera medicación y semanalmente durante un periodo de dos meses.

Las torundas con muestras de tráquea fueron trabajadas en pools de cuatro muestras/pool debidamente identificados y colocados en viales de plástico con $1 \mathrm{ml}$ de PBS pH 7.1 para extraer células de mycoplasmas. Luego los viales fueron colocados en la microcentrífuga por 10 minutos.

Posteriormente, se eliminó todo el sobrenadante y se agregó $25 \mu \mathrm{l}$ de agua destilada estéril, fueron llevados a ebullición a $100^{\circ} \mathrm{C}$ por 10 minutos, a congelación a $-20^{\circ} \mathrm{C}$ por 10 minutos y finalmente a la microcentrífuga por 5 minutos.

Los iniciadores utilizados son altamente específicos debido a que fueron seleccionados a partir de una secuencia conocida de nucleótidos del gen que codifica la fracción $16 \mathrm{~S}$ del ARNr en el $M$. synoviae (región variable).

En la preparación del Mix se utilizó por cada pool: $31 \mu$ de agua destilada deionizada; $5 \mu$ l de 10X PCR buffer II
(100mM Tris-HCl, $500 \mathrm{mM} \mathrm{KCl);} 11(10 \mathrm{mM})$ de dATP; $1 \mathrm{ml}(10 \mathrm{mM})$ de dCTP; $1 \mu \mathrm{l}(10 \mathrm{mM})$ de dGTP; $1 \mu \mathrm{l}(10 \mathrm{mM})$ de dTTP; $0.5 \mu \mathrm{l}$ (20pmoles) de MS-LF; $0.5 \mu l$ (20pmoles) de MS-LR; $0.25 \mu \mathrm{l}(1.25 \mathrm{U})$ de Amplitaq ADN polimerasa recombinante y $4 \mu \mathrm{l}(25 \mathrm{mM}) \mathrm{de}$ $\mathrm{MgCl}_{2}$

Se prepararon viales agregando $45 \mu \mathrm{l}$ de Mix y 2 gotas de aceite mineral para evitar la evaporación de los reactivos. Luego, se agregó $5 \mu \mathrm{l}$ del sobrenadante de la muestra de ADN problema en cada vial. Se incluyeron un control positivo representado por la cepa K947 MS y un control negativo representado por agua destilada deionizada.

Ampliacion del ADN se realizaron con viales que fueron llevados a un termociclador Perkin Elmer 480 bajo las condiciones siguientes: 40 ciclos de desna-turalización a $94^{\circ} \mathrm{C}$ por un minuto, hibridación a $55^{\circ} \mathrm{C}$ por un minuto y extensión a $72^{\circ} \mathrm{C}$ por dos minutos; 1 ciclo de $72^{\circ} \mathrm{C}$ por cinco minutos y conservación a $4^{\circ} \mathrm{C}$ por tiempo indefinido.

Para la visualización del producto ADN se preparó el gel de agarosa al $1.5 \%$ con la siguiente formula: $0.26 \mathrm{~g}$ de agarosa $\mathrm{ADN} ; 0.38 \mathrm{~g}$ de synergel; $2 \mu \mathrm{l}$ de etanol absoluto y $50 \mathrm{ml}$ de solución buffer IX TEA.

Los ingredientes fueron vertidos y disueltos en un matraz y éste fue colocado en un horno microondas durante 2 minutos aproximadamente hasta que se diluyeron los ingredientes completamente. Posteriormente se le agregó a la mezcla $100 \mathrm{ml}$ (40ng) de bromuro de etidio y se homogenizó cuidadosamente.

El gel fue colocado en una cámara de gel electroforesis. Se cortó cinta parafilm y se colocó sobre ella $3 \mu 1$ de tracking dye para cada muestra, se tomó $10 \mu \mathrm{l}$ de la muestra introduciendo cuidadosamente el tip hasta el fondo del vial, presionando el émbolo para que se formen burbujas y se elimine el remanente de aceite, se mezcló la muestra con el tracking dye, se colocó en el hoyo corres- 
pondiente y se agregó buffer hasta cubrir el gel. Se conectaron los electrodos y se dejó correr las muestras durante 35 minutos. Finalmente se fotografió el gel en el transiluminador.

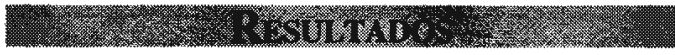

\section{Pre-medicación}

Todas las muestras de tráquea obtenidas de dieciséis aves antes de la medicación a las $11,12,13,14,15$ y 29 semanas de edad fueron positivas a $M$. synoviae por la prueba de Reacción en Cadena por la Polimerasa (Cuadro 1).

\section{Post-medicación}

Los resultados de las pruebas ejecutadas en las muestras tomadas desde una semana después a la primera medicación (Cuadro 2 y Figura 1).

\section{Discusidar}

La prueba de PCR tiene ventajas importantes sobre los métodos tradicionales de diagnóstico debido a que además de ser muy sensitiva en detectar mycoplasmas en estadios iniciales de infección, los resultados se pueden tener en pocas horas (Levisohn, 1999) y si se usan iniciadores apropiados evidencia alta especificidad para identificar cepas específicas de campo o cepas vacunales vivas lo que es de valor para descubrir la fuente de infección (Kleven, 1999). No se conoce que tanto la medicación puede afectar su sensibilidad, la importancia del presente estudio radica en que es un aporte al conocimiento de la acción o influencia de la tiamulina sobre la presencia o cantidades de células micoplásmicas capaces de ser detectadas por PCR.

La literatura menciona varios antibióticos eficaces contra mycoplasmas aviares, dentro de ellos la tilosina en la que se ha podido determinar el desarrollo de algún grado de resistencia contra los mycoplasmas, las
Cuadro 1.Persistencia del $M$ synoviae (MS) en gallinas de postura comercial previo al tratamiento y evaluadas mediante la prueba PCR.

\begin{tabular}{ccccc}
\hline \begin{tabular}{c} 
Edad de las $\begin{array}{c}\text { aves } \\
\text { (semana) }\end{array}$ \\
\cline { 2 - 5 }
\end{tabular} & \multicolumn{4}{c}{$\begin{array}{c}\text { Recuperación de } M \text {. synoviae en } \\
\text { tráquea }\end{array}$} \\
\cline { 2 - 5 } 11 & Pool 1 & Pool 2 & Pool 3 & Pool 4 \\
12 & + & + & + & + \\
13 & + & + & + & + \\
14 & + & + & + & + \\
15 & + & + & + & + \\
29 & + & + & + & + \\
\hline
\end{tabular}

Pool $=$ Grupo de cuatro muestras de tráquea

$+\quad=$ Presencia de ADN-MS

quinolonas de tercera generación como la enrofloxacina y el Fumarato Hidrogenado de Tiamulina que se usó en el presente estudio, como los más importantes.

En los planteles de postura comercial es más difícil evitar la contaminación de los lotes con $M$. synoviae debido a que este microorganismo se caracteriza por su rápida transmisión horizontal (Kleven, 1997) que es favorecida por la elevada concentración de aves y el sistema de crianza de edades múltiples en donde existe una elevada prevalencia (Yamamoto, 1986; Ewing et al., 1996; Díaz, 1999; Gonzáles, 1999) lo cual permite que las gallinas de postura comercial se infecten a temprana edad. En nuestro trabajo se detectó $M$. synoviae en aves de 11 semanas de edad.

En el presente estudio la prueba de PCR detectó ADN-MS en mucosa traqueal de aves no medicadas a las $11,12,13,14,15$ y 29 semanas de edad, demostrando la persistencia del agente a nivel de la mucosa traqueal. Un resultado similar fue obtenido por Khan et al. (1996) en reproductoras in- 
Cuadro 2. Efecto de la medicación con Fumarato Hidrogenado de Tiamulina sobre la persistencia del M. synoviae, en gallinas de postura comercial mediante la prueba PCR.

\begin{tabular}{cccccc}
\hline \multirow{2}{*}{$\begin{array}{c}\text { Edad de las aves } \\
\text { (semanas) }\end{array}$} & Días & \multicolumn{5}{c}{ M. synoviae en tráquea por } \\
\cline { 2 - 6 } & Post medicación & \multicolumn{3}{c}{ Medicadas } & \multicolumn{3}{c}{ No medicadas } \\
\cline { 2 - 6 } & Primera medicación & Pool 1 & Pool 2 & Pool 3 & Pool 4 \\
\hline 30 & 7 & + & + & + & + \\
31 & 14 & + & + & + & + \\
32 & 21 & + & + & + & + \\
33 & 28 & + & + & + & + \\
34 & Segunda medicación & $\mathrm{NR}$ & $\mathrm{NR}$ & $\mathrm{NR}$ & $\mathrm{NR}$ \\
35 & 7 & + & + & + & + \\
36 & 14 & + & + & + & + \\
37 & 21 & + & + & + & + \\
38 & 28 & + & + & + & + \\
39 & & + & + & & + \\
\hline
\end{tabular}

Pool = Grupo de cuatro muestras de tráquea

$\mathrm{NR}=$ No se realizó el muestreo.

$+\quad=$ Presencia de ADN-MS



Figura 1. Efecto de la medicación con Fumarato Hidrogenado de Tiamulina sobre la persistencia del Mycoplasma synoviae, evaluado mediante la prueba PCR en gallinas de postura comercial. 
fectadas con $M$. synoviae. Igualmente otro estudio realizado en pollos y pavos a los que se les inoculó la cepa WVU1853 de $M$. synoviae y fueron sometidos a un seguimiento por PCR, se observó que éstos se convirtieron en positivos y mantuvieron esa condición hasta finalizar el experimento (Goll y Lauerman, 1998).

Después del tratamiento con tiamulina la prueba PCR dio positivo a $M$. synoviae en ocho muestreos consecutivos realizados desde las 31 semanas de edad hasta las 39 semanas de edad demostrando la presencia del $M$. synoviae luego de la medicación, estos resultados concuerdan con los obtenidos por Kempf et al.(1994) quienes al utilizar enrofloxacina en aves infectadas con $M$. gallisepticum detectaron el agente en todas las semanas de estudio mediante PCR. No obstante se debe considerar la menor acción de la enrofloxacina sobre los mycoplasmas, demostrada en las pruebas de sensibilidad antibiótica realizadas en cepas estándares y de campo utilizando enrofloxacina y tiamulina en donde la primera necesitó concentraciones inhibitorias superiores $(0.1$ y $0.5 \mu \mathrm{g} / \mathrm{ml})$ a la segunda $(0.025$ y 0.25 $\mu \mathrm{g} / \mathrm{ml}$ ) tanto para M.gallisepticum como M.synoviae (Hannan et al., 1997).

En un reporte de campo publicado por Icochea et al. (1999) en pavos infectados con M. gallisepticum la tiamulina además de controlar eficientemente el cuadro clínico afectó la detección de ADN-MG por PCR a la quinta y sexta semana post-infección, lo cual puede ser explicado por la mayor susceptibilidad demostrada in vitro por el M. gallisepticum $\left(\mathrm{CIM}_{90}=0.025 \mu \mathrm{g} / \mathrm{ml}\right) v s \mathrm{M}$. synoviae $\left(\mathrm{CIM}_{90}=0.25 \mu \mathrm{g} / \mathrm{ml}\right)$ frente al antibiótico (Hannan et al., 1997).

En la persistencia del mycoplasma se puede considerar la posibilidad de detectar ADN de células no viables, no obstante puede ser difícil que organismos no viables permanezcan en las aves mucho tiempo después del tratamiento debido a que ellos pueden ser eliminados por el proceso natural de degradación de ADN.

Por otro lado el uso de la tiamulina a una dosis de $33 \mathrm{mg} / \mathrm{kg}$ administrada en el agua de bebida, a nivel de la mucosa traqueal podría haber disminuido la cantidad de mycoplasmas pero a niveles aún detectables por PCR probablemente por la menor susceptibilidad del M. synoviae al antibiótico.

También se debe considerar la ubicación del $M$. synoviae a nivel de células epiteliales traquéales, como un factor que probablemente dificulte la acción del antibiótico.

Asimismo el trabajar muestras de tráquea en pools puede identificar erróneamente como positivas algunas muestras que son negativas al $M$. synoviae, sin embargo en las infecciones micoplásmicas es necesario que tanto el diagnóstico como los resultados de medicación deben ser de lotes y no de aves individuales.

Los resultados del presente estudio evidencian que la administración de tiamulina no elimina la infección por $M$. synoviae, a nivel de mucosa traqueal, por lo cual no modifica la persistencia del agente en aves portadoras ni en sintomáticas, pero el efecto positivo de este medicamento podria ser disminuir la transmisión horizontal o vertical y prevenir las lesiones de esta enfermedad, significando mejores índices productivos.

- La medicación con Fumarato Hidrogenado de Tiamulina administrada en el agua de bebida a razón de $33 \mathrm{mg} / \mathrm{kg}$ no eliminó al $M$. synoviae de la mucosa traqueal de las aves infectadas crónicamente.

- El Mycoplasma synoviae fue demostrado en la mucosa traqueal des- 
de las 11 semanas hasta más de 39 semanas de edad, mediante la prueba de PCR antes y después de la medicación.



Los primers fueron proporcionados por el Dr. Lauerman, L. H. del Laboratorio Estatal de Diagnóstico Veterinaria de Ala-bama, Auburn, USA



1. Díaz, E. G. S. 1999. Prevalencia de Mycoplasma gallisepticum y $M$. synoviae en gallinas de postura comercial de la provincia de Chincha. Tesis Bachillerato. Fac. Med. Vet. UNMSM. Lima. p. 47.

2. Ewing, M. L.; L. H. Lauerman; S. H. Kleven y M. B. Brown. 1996. Evaluation of diagnostic procedures to detect Mycoplasma synoviae in commercial multiplier breeder farms and commercial hatcheries in Florida. Avian Dis. 40(4):798-806.

3. Goll, F. y L. H. Lauerman. 1998. Identification of Mycoplasma synoviae infected chickens and turkeys by culture, polymerase chain reaction assay and serology. In: $12^{\text {th }}$ Congress of the IOM. Sydney, Australia. p.61-62.

4. Gonzáles, V.R. 1999. Detección de Mycoplasma gallisepticum y $M$. synoviae mediante el diagnóstico microbiológico y PCR en gallinas de postura de la provincia de Chincha. Tesis Licenciatura. Fac. Biol. Univ. Part. Ricardo Palma. Lima, p. 52.

5. Hannan, P. C.; G. D. Windsor; A. Jong; N. Schmeer y M. Stegemann.
1997. Comparative susceptibilities of various animal pathogenic mycoplasmas to fluoroquinolones. Antimicrob. Agents Chemother. 41(9):2037-2040.

6. Icochea, E.; A. Ramírez; N. Noé y S. Levisohn. 1999. Diagnóstico de sinusitis infecciosa en pavos por ADN-PCR para Mycoplasma gallisepticum en Perú. XVI Congreso Latinoamericano de Avicultura. APA. ALA. Lima, p. 273.

7. Kempf, I; F. Gesbert; M. Guittet y G. Bennejean. 1994. Mycoplasma gallisepticum infection in drug-treated chickens: Comparison of diagnosis methods including polymerase chain reaction. J. Vet. Med. B. 41(9):597-602.

8. Khan, M. I.; J. Schultz; A. V. Nguyen; L. H. Lauerman; A. A. Fadl; T. I. Phyllis y K. Takeshita. 1996. Detection of lateral spread of Mycoplasma gallisepticum and $M$. synoviae infections in broiler breeder chickens using DNA based PCR kit. Inédito.

9. Kleven, S. H. 1997. Mycoplasma synoviae infection. In: Diseases of poultry. $10^{\text {th }}$ ed., p. $220-228$. Calnek (edit). Iowa, USA. Iowa Univ. Press.

10. Kleven, S. H. 1999. Control y erradicación de micoplasmosis. XVI Congreso Latinoamericano de Avicultura. (Conferencia) APA. ALA. Lima. p. 19-23.

11. Levisohn, S. 1999. Diagnóstico serológico y molecular de mycoplasmas aviares. XVI Congreso Latinoamericano de Avicultura. (Conferencia). APA. ALA. Lima, p. 53-54.

12. Yamamoto, R. 1986. Prevalence of Mycoplasma gallisepticum and $M$. synoviae in commercial layers in Southern and Central California. Avian Dis. 30(3): 519-526. 